\title{
Assessment of Teaching Strategy among Undergraduate Medical Students of Clinical Sciences
}

\author{
Sadaf Jabeen, Asad Raza Jiskani, Hina Khan, Fouzia Kirmani, Nighat Seema, Devi Kumari
}

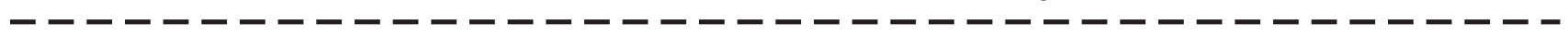

ABSTRACT

Objective: To assess the preferred teaching strategies for undergraduate medical students of clinical sciences.

Study Design and Setting: -This cross-sectional study was conducted among the $4^{\text {th }}$ and $5^{\text {th }}$ year students of clinical sciences at Al-Tibri Medical College and Hospital Isra University. Karachi campus.

Methodology: All medical students of $4^{\text {th }}$ and $5^{\text {th }}$ year were enrolled and included for this study from May 2018 to June 2018 and absentees were excluded. A questionnaire was given to students in which they opted for the best teaching aid and strategy. Data was collected and analysed by principle Investigator. Demographic variables included were gender and year of M.B.B.S. Descriptive statistics was carried out via frequency and percentages.

Results: A total of 166 Students, 82 from $4^{\text {th }}$ year and 84 from $5^{\text {th }}$ year were reviewed. Among $4^{\text {th }}$ year students; preference in academic teaching aids were white boards and multimedia and were equally preferred and for clinical teaching the most preferred aid was Out Patient Department (OPD)/clinical rotation. Among 5th year medical students' multimedia was most preferred for academic teaching and for clinical teaching the most preferred teaching aid was clinical based learning, i.e. $32(38.1 \%)$.

Conclusion: White board, multimedia, were the most preferred teaching methods for academic teaching and bed side teaching and clinical based learning were highly preferred teaching method for clinical teaching among both cohorts of $4^{\text {th }}$ and $5^{\text {th }}$ year medical students. Therefore, approaches for improvement of the preferred teaching methods and establishing better facilities for students can be improve both knowledge and skills among clinical students.

Key words: Academic Teaching, Clinical Sciences, Learning Styles, Preferences, Teaching Aid.

\section{INTRODUCTION:}

The purpose of diversified teaching aids is to facilitate learning and to encourage the learners to learn more effectively ${ }^{1}$. The learning styles can be described as an individual's consistent way of perceiving, processing and retaining new information. Educational researchers have

Sadaf Jabeen
Assistant Professor, Department of General Surgery
Al-Tibri Medical College and Hospital, Karachi
Asad Raza Jiskani
Associate Professor, Department of Community Medicine,
Director Academics Clinical \& In charge Medical Education
Al-Tibri Medical College and Hospital, Karachi
Hina Khan
Associate Professor, Department of Anatomy,
Deputy Director Research \& Coordinator Medical Education
Al-Tibri Medical College and Hospital, Karachi
Email: drhinasalman @ gmail.com
Fouzia Kirmani
Lecturer, Department of Anatomy
Al-Tibri Medical College and Hospital, Karachi
Nighat Seema
Assistant Professor, Department of Pediatrics
Al-Tibri Medical College and Hospital, Karachi
Devi Kumari
Senior Lecturer, Department of Anatomy
Al-Tibri Medical College and Hospital, Karachi
Received: 12-03-2019
Accepted: 04-09-2019

shown an increasing interest in the learning styles, the related instructional methods and teaching techniques ${ }^{1}$. This interest is spurred by aiming to help the students by making them more capable and successful learners. In the complex setting of a medical school; it is essential to incorporate various learning approaches in teaching and learning that is best suited with the student's needs. In developing countries, there is an exponential increase of medical institutions catering huge number of medical students and it becomes a challenge to teach large number of students per class $^{2}$.Therefore, research is needed to identify the need assessment of students in relation to their day to day learning activities $^{3}$. Therefore, it is fundamental for educators to realize that every student have different learning style and for that they should tailor instructions accordingly to facilitate learning. ${ }^{4}$ Various instructional strategies used for academic teaching of fourth and fifth year medical students include lectures (board and multimedia), tutorials, practical, assignment, problem based learning, and team based learning etc. ${ }^{5}$. For clinical teaching; the methods used are bed side teaching, OPD, examination of patient etc. Now from past few years electronic learning or e-learning is very famous among students which comprised of lectures, videos on internet, animated description of topic which helps student to understand the theme and retain for long ${ }^{6}$. Having knowledge on the learners' learning styles is a vastly underutilized theory to improve the classroom instructions. The learning style information can also benefit the students 
as it would help them in formulating the appropriate learning strategies for enhancing their learning ${ }^{7}$. To the best of our knowledge, none of the studies have correlated the preferences of the instructional methods with the learning styles of the medical students ${ }^{8}$.The quality of medical education depends upon various factors like curriculum, college administration, infrastructure, patient exposure, faculty expertise in the subject and their knowledge, exposure and training in teaching-learning methodology. Moreover medical education in the past decade is witnessing a paradigm shifted from teacher centric to student centered mode. ${ }^{9}$ Therefore, student opinion and preferences matter the most before introduction of any additions, deletions or modifications in the way the course is conducted. At the same time students differs in age, place, ethnicity, level of preparedness, learning styles and preferences etc. ${ }^{10}$. Therefore it becomes a responsibility of every medical institute and teacher to meet the individual's educational need about the knowledge, attitude, and skills of the subject. One of the most important ways to strengthen the medical education at content delivery level is to assess student perception about teaching- learning methodology. Numerous teaching-learning strategies are practiced throughout MBBS course, to promote participation and interest of students and facilitate learning. These methods include didactic lectures, role plays, seminars, case studies, demonstrations through videotapes, problem based learning (PBL), tutorials etc. ${ }^{11}$. The aim of the present study was to find out the most preferred instructional methods in clinical and academic teaching among medical students of clinical years $\left(4^{\text {th }}\right.$ and $5^{\text {th }}$ year).

\section{METHODOLOGY:}

A cross sectional study using convenient sampling was done among fourth and fifth year M.B.B.S student of AlTibri Medical College Karachi, Pakistan for a period of one month from $15^{\text {th }}$ May 2018 to $15^{\text {th }}$ June 2018. Ethical approval was obtained from the IRB. All the students of the respective clinical year were selected, therefore a total of 166 students were included among which 82 student from $4^{\text {th }}$ year and 84 students from $5^{\text {th }}$ year. Students present at the time of data collection were selected for the study and those who are absent were excluded.

A questionnaire was distributed amongst the students, asking them about preferred teaching strategy for academic and clinical teaching. Questions such as the current method of teaching present, better option for learning a topic, method of teaching which helps to retain a topic and lastly the preferred method of teaching by the students was asked. Questions were asked in serial order and students had to select their preferred teaching option. Data was analysed using SPSS version 20.0. Data was collected, analysed and kept confidential. Descriptive statistics included gender and year of M.B.B.S. Frequency and percentages were calculated and presented.

\section{RESULTS:}

A total of 166 of students, 82 from $4^{\text {th }}$ year and 84 from $5^{\text {th }}$ year MBBS were reviewed. The preferred method of academic teaching by $4^{\text {th }}$ year medical students was white board and multimedia, $26(31.7 \%)$ each. Least preferred method was assignments by $\mathrm{n}=03$ (3.7\%) of students. Among $5^{\text {th }}$ year medical students; the preferred academic teaching was multimedia, by $n=32(38.1 \%)$ students followed by group discussion by $\mathrm{n}=22(26.2 \%)$ while least preferred methods were tutorial and assignments, by $\mathrm{n}=01(1.2 \%)$ student. The preferred method for clinical teaching among $4^{\text {th }}$ year medical students was O.P.D $n=27(32.9 \%)$; followed by wards $n=19(23.2 \%)$ while least preferred methods were history taking and multimedia as $\mathrm{n}=03(3.7 \%)$ students for each. The preferred strategy for clinical teaching among $5^{\text {th }}$ year medical students was clinical based learning at $\mathrm{n}=29$ (34.5\%) followed wards as $n=25(29.8 \%)$; while least preferred method in this cohort was clinical examination $\mathrm{n}=03(3.7 \%)$. Figure $1-2$

Figure 1- The Preferred Academic Teaching Methods among 4 and $5^{\text {th }}$ Year MBBS Students

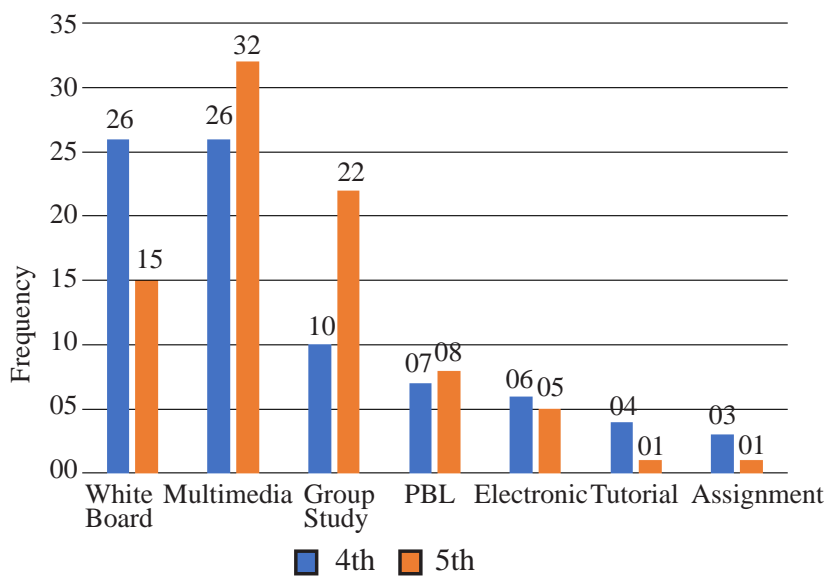

Figure 2- The Preferred Clinical Teaching Methods among 4 and $5^{\text {th }}$ Year MBBS Students

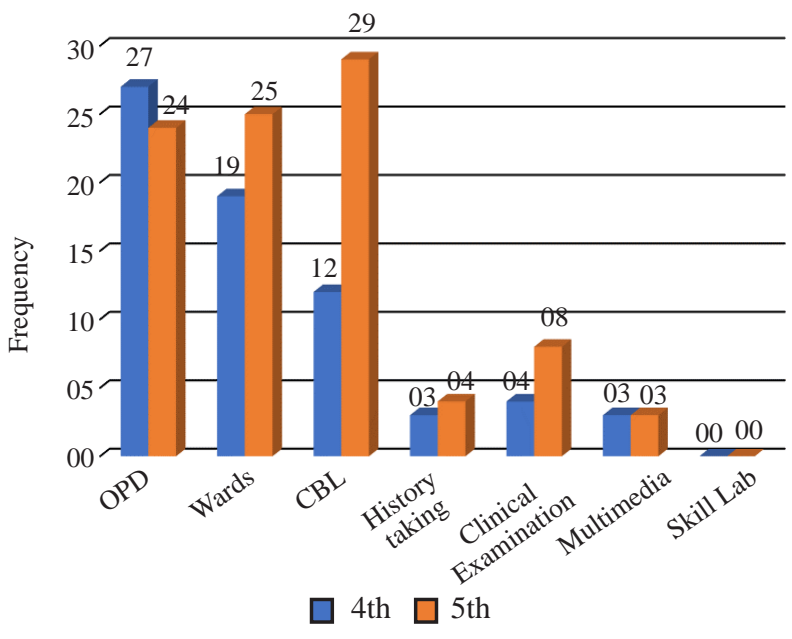




\section{DISCUSSION:}

The preferred method of academic teaching by $4^{\text {th }}$ year medical students was white board and multimedia, 26 $(31.7 \%)$ each. Least preferred method was assignments by $\mathrm{n}=03(3.7 \%)$ of students. Among $5^{\text {th }}$ year medical students; the preferred academic teaching was multimedia, by $n=32$ (38.1\%) students followed by group discussion by $\mathrm{n}=22$ (26.2\%) while least preferred methods were tutorial and assignments, by $\mathrm{n}=01(1.2 \%)$ student. These results were incongruent with the study of Gupta et al; in which from 130 students, $n=59(45.4 \%)$ preferred lectures followed by group discussion $n=26(27.7 \%)$ students while tutorial was preferred by only $n=28(21.5 \%)$ students. Another study declared that the best teaching-learning mode was blackboard teaching chosen by $n=58(44.6 \%)$ students followed by multimedia $\mathrm{n}=47(36.1 \%)$ students ${ }^{12}$. A similar study by Priyadarshini et al. revealed that $31 \%$ of students preferred blackboard teaching over multimedia ${ }^{13}$.In another study by Papanna et al., the preferred mode of teaching was blackboard, by (51.4\%) of students followed by multimedia, by (40.9\%) students. ${ }^{14} \mathrm{~A}$ study by Mohan et al, reported in their study that both white board and multimedia were equally preferred among the students, similar to the finding of our study of $4^{\text {th }}$ year students ${ }^{15}$. Another study by Atif et al. showed that the preferred method of academic teaching among the students was multimedia ${ }^{16}$.In a study by Kharbet al. $39.5 \%$ of students preferred group discussion while $27.8 \%$ students preferred lectures including both white board and multimedia ${ }^{17}$. In another study byNaqvi SH et al, this was similar to our study, where black board teaching was preferred over other teaching $\operatorname{aid}^{18}$.

In our study; the preferred method for clinical teaching among $4^{\text {th }}$ year medical students was O.P.D $n=27(32.9 \%)$; followed by wards $n=19(23.2 \%)$ while least preferred methods were history taking and multimedia as $\mathrm{n}=03$ (3.7\%) students for each. The preferred strategy for clinical teaching among $5^{\text {th }}$ year medical students was clinical based learning at $n=29(34.5 \%)$ followed wards as $n=25(29.8 \%)$; while least preferred method in this cohort was clinical examination $n=03(3.7 \%)$. The preferred clinical strategy were similar with the study of Papanna et al; in which $81.5 \%$ students preferred bed side teaching whether in wards or O.P.D. to develop clinical skills ${ }^{14}$. Mahmood A et al reported that problem based learning and case studies were the most preferred teaching aid among the students. ${ }^{19}$.Fatima SS et al reported in their study of 98 students that the concept of "flipped classroom" i.e. interactive 2-way session were most preferred by undergraduate $4^{\text {th }}$ year medical students ${ }^{20}$.In a study on 138 medical students of $2^{\text {nd }}$ undergraduate year by Holambe $\mathrm{VM}$ et al reported that the most preferred mode for theory and practical teaching by students was focused group discussion and bedside clinic respectively and the most common obstacle faced by students during theory and practical learning was one way, non-interactive teaching ${ }^{21}$. In a study by Madhukumar $\mathrm{S}$ et al on undergraduate medical students of all years reported that from 685 students, more than half, i.e. 53\% of the students preferred blackboard and $47 \%$ preferred power-point presentations. Majority of students preferred bed-side teaching $(71 \%)$ over video and animation lectures $^{22}$.Neetha CS et al in another study on 146 medical students reported that the most preferred mode of teaching was blackboard, i.e. among $54.79 \%$ of students ${ }^{23}$.

Therefore it was recommended that providing training and opportunities to the medical educators for the development and understanding of the students' learning style preferences can result in a greater comprehension and consideration of the unique learning needs of each student. Correlating the students' learning style preferences and instructional needs can assist the teachers in using appropriate teaching-learning instructional practices and it can also provide personalized interventions for enhancing the learning.

Limitations of the study included observer bias, limited sample size and being conducted at a single center. Further recommendations for large scale multi-centric studies with different teaching methods are warranted to work on improvement and facilitate the learning.

\section{CONCLUSION:}

White board, multimedia, were the most preferred teaching methods for academic teaching and bed side teaching and clinical based learning were highly preferred teaching method for clinical teaching among both $4^{\text {th }}$ and $5^{\text {th }}$ year medical students. Therefore, approaches for improvement of the preferred teaching methods and establishing better facilities for students can be improve both knowledge and skills among clinical students.

\section{REFERENCES:}

1. Regmi K. A Review of Teaching Methods--Lecturing and Facilitation in Higher Education (HE): A Summary of the Published Evidence. Journal of Effective Teaching. 2012;12(3):61-76.

2. Choudhary R, Dullo P, Tandon RV. Gender differences in learning style preferences of first year medical students. Pak J Physiol. 2011;7(2):42-5.

3. Liew SC, Sidhu J, Barua A. The relationship between learning preferences (styles and approaches) and learning outcomes among pre-clinical undergraduate medical students. BMC medical education. 2015;15(1):44-51.

4. Collins J. Education techniques for lifelong learning: giving a PowerPoint presentation: the art of communicating effectively. Radiographics. 2004;24(4):1185-92.

5. Sarabi-Asiabar A, Jafari M, Sadeghifar J, Tofighi S, Zaboli R, Peyman H, Salimi M, et al. The relationship between learning style preferences and gender, educational major and status in first year medical students: A survey study from Iran. Iranian Red Crescent Medical Journal. 2015;17(1):1-6.

6. Nuzhat A, Salem RO, Quadri MS, Al-Hamdan N. Learning style preferences of medical students: a single-institute experience from Saudi Arabia. Int J Med Educ.2011;2:70-3. 
7. Nirmal KS, Amit B, Simerjit S, Adinegara LA. Learning preferences of clinical students: a study in a Malaysian medical college. International Journal of Medicine and Public Health. 2013;3(1):60-3.

8. Williamson MF, Watson RL. Learning styles research: understanding how teaching should be impacted by the way learners learn part II: understanding how learners prefer to receive information. Christian Education Journal. 2006;3(2): 343-61.

9. Nanda B, Manjunatha S. Indian medical students' perspectives on problem-based learning experiences in the undergraduate curriculum: One size does not fit all. Journal of Educational Evaluation for Health Professions. 2013;10(1):11-18

10. Gade S, Chari S, Dasgupta S. Perception of the Medical Students of a Private Medical College on their Future Career Indian J of Applied. Research. 2013;3(10):1-4.

11. Patil U, Vaidya S, Jore S, Parekh M. MS Patwardhan Study of Student's Feedback on Present Teaching and Learning Patterns. Int J of Recent Trends in Sci And Tech. 2012;4(1):345.

12. Gupta SS, Rathod AD. A Study on preferences of I MBBS Students about teaching-Learning Methods. Journal of Education Technology in Health Sciences. 2016;3(1):20-2.

13. Priyadarshini KS, Shetty HV, Reena R. assessment of different teaching aid and teaching methods for the better perception of Biochemistry by 1st MBBS students. Journal of evolution of medical and dental sciences. 2012;1(6):1159-65.

14. Papanna KM, Kulkarni V, Tanvi D, Lakshmi V, Kriti L, Unnikrishnan B, Akash S, et al. Perceptions and preferences of medical students regarding teaching methods in a Medical College, Mangalore India. African health sciences. 2013;13(3): 808-13.

15. Mohan L, Kamath A, Manish M, Eesha B. Students' attitudes towards the use of audio visualaid during didactic lectures in pharmacology. Journal of Clinical and Diagnostic Research. 2010;4(6):3363-8.
16. Atif M, Fahmida K, Mukarram A, Saima E, Kamran A, Qureshi MA. Perception and preferences of undergraduate medical students regarding the use of contemporary teaching aid at Dow International Medical College, Karachi. Journal of the Dow University of Health Sciences. 2011;5(1):34-6.

17. Kharb P, Samanta PP, Jindal M, Singh V. The learning styles and the preferred teaching-learning strategies of first year medical students. Journal of clinical and diagnostic research: JCDR. 2013;7(6):1089-92.

18. Naqvi SH, Mobasher F, Afzal MA, Umair M, Kohli AN, Bukhari MH. Effectiveness of teaching methods in a medical institute: perceptions of medical students to teaching aid. J Pak Med Assoc. 2013;63(7):859-64.

19. Mahmood A, Khatoon F, Ali M, Ejaz S, Qureshi MA. Perceptions and preference of contemporary teaching methods among university students of Pakistan-A cross-sectional survey. IOSR J Nursing Health Sci. 2012;1(1):6-10.

20. Fatima SS, Arain FM, Enam SA. Flipped classroom instructional approach in undergraduate medical education. Pakistan Journal of Medical Sciences. 2017;33(6):1424.

21. Holambe VM, Thakur NA, Giri PA. Student's preferences for learning in medical education. International Journal Of Community Medicine And Public Health. 2017;2(3):328-30.

22. Madhukumar S. Usage of Teaching Aids in A Medical CollegeStudents Perceptions. Indian Journal of Public Health Research \& Development. 2017;8(4):89-93.

23. Neetha CS, Nandini T, Padmanabha TS. Students' preferences of teaching methods and aids in a medical college-A crosssectional study. National Journal of Physiology, Pharmacy and Pharmacology. 2019;9(8):763-6. 